\title{
GRAZERS, PRODUCER STOICHIOMETRY, AND THE LIGHT : NUTRIENT HYPOTHESIS REVISITED
}

\author{
Spencer R. Hall, ${ }^{1,5}$ Mathew A. Leibold, ${ }^{2}$ David A. Lytle, ${ }^{3}$ and Val H. Smith ${ }^{4}$ \\ ${ }^{1}$ Department of Biology, Indiana University, 1001 East 3rd Street, Bloomington, Indiana 47405 USA \\ ${ }^{2}$ Section of Integrative Biology, University of Texas, Austin, Texas 78712 USA \\ ${ }^{3}$ Department of Zoology, Oregon State University, Corvallis, Oregon 97331 USA \\ ${ }^{4}$ Program in Ecology and Population Biology, Department of Ecology and Evolutionary Biology, University of Kansas, \\ Lawrence, Kansas 66045 USA
}

\begin{abstract}
The stoichiometric light: nutrient hypothesis (LNH) links the relative supplies of key resources with the nutrient content of tissues of producers. This resource-driven variation in producer stoichiometry, in turn, can mediate the efficiency of grazing. Typically, discussions of the LNH attribute this resource-stoichiometry link to bottom-up effects of light and phosphorus, which are mediated through producer physiology. Emphasis on bottom-up effects implies that grazers must consume food of quality solely determined by resource supply to ecosystems (i.e., they eat what they are served). Here, we expand upon this largely bottomup interpretation with evidence from pond surveys, a mesocosm experiment, and a model. Data from shallow ponds showed the "LNH pattern" (positive correlation of an index of light:phosphorus supply with algal carbon:phosphorus content). However, algal carbon: phosphorus content also declined as zooplankton biomass increased in the ponds. The experiment and model confirmed that this latter correlation was partially caused by the various bottom-up and top-down roles of grazers: the LNH pattern emerged only in treatments with crustacean grazers, not those without them. Furthermore, model and experiment clarified that another bottom-up factor, natural covariation of nitrogen:phosphorus ratios with light: phosphorus supply (as seen in ponds), does not likely contribute to the LNH pattern. Finally, the experiment produced correlations between shifts in species composition of algae, partially driven by grazing effects of crustaceans, and algal stoichiometry. These shifts in species composition might shape stoichiometric response of producer assemblages to resource supply and grazing, but their consequences remain largely unexplored. Thus, this study accentuated the importance of grazing for the LNH; deemphasized a potentially confounding, bottom-up factor (covarying nitrogen:phosphorus supply); and highlighted an avenue for future research for the LNH (grazer-mediated shifts in producer composition).
\end{abstract}

Key words: algal species composition; ecological stoichiometry; grazing; light: nutrient hypothesis; nitrogen : phosphorus supply; ponds.

\section{INTRODUCTION}

Primary productivity in aquatic ecosystems depends critically both upon light availability and upon the supplies of nutrients such as nitrogen and phosphorus (Smith 1979). These key resources govern the standing crop of primary producers, which then support growth and reproduction of higher trophic levels. However, relative supplies of light and nutrients may also shape nutritional quality of these primary producers (Sterner et al. 1997). In fact, the stoichiometric "light: nutrient hypothesis" (LNH) states that ecosystems receiving high supplies of light relative to phosphorus tend to yield phosphorus-poor producers (resulting in a high tissue C:P ratio). In contrast, systems receiving low light: phos-

Manuscript received 1 June 2006; revised 29 September 2006; accepted 27 October 2006. Corresponding Editor: K. L. Cottingham.

${ }^{5}$ E-mail: sprhall@indiana.edu phorus supplies should yield more phosphorus-rich producers (i.e., low tissue C:P ratios; Sterner et al. 1997, Sterner and Elser 2002). This resource-driven stoichiometric plasticity is potentially important because nutrient-rich grazers, such as the crustacean zooplankton Daphnia, respond sensitively to nutrient content of their algal food. Phosphorus-poor food can yield phosphorus rather than carbon-limited grazing; nutrient-limited herbivory, in turn, reduces secondary production and decreases efficiency of grazing (Urabe and Watanabe 1992, Sterner 1993, Urabe and Sterner 1996, Urabe et al. 1997, DeMott et al. 1998, Elser et al. 2001). Thus, via stoichiometric food quality-related mechanisms, the relative supplies of light and phosphorus may govern fundamental processes in ecosystems, such as the transfer and allocation of energy and nutrients among trophic levels (Andersen 1997, Sterner et al. 1997, 1998, Sterner and Elser 2002).

Most discussions of the light: nutrient hypothesis to date have emphasized the bottom-up linkage between 
resource supplies and producer stoichiometry. This natural emphasis reflects evidence that decreasing light supply can increase the nutrient content of algal cells grown in grazer-free, single species laboratory cultures (Healey 1985, Urabe and Sterner 1996, Hessen et al. 2002), and phytoplankton assemblages growing in field enclosures with reduced grazing pressure (Diehl et al. 2002, 2005). The physiological mechanisms thought to be involved are straightforward: low light availability (driven by low incident photon flux rates, and/or by strong light attenuation within the water column; Huisman and Weissing 1995) causes light-limited algae to allocate high levels of phosphorus to light-harvesting cellular machinery and to store excess phosphorus intracellularly (Hessen et al. 2002, Sterner and Elser 2002). Another possible bottom-up process has received much less attention. As systems become more enriched (and experience lower light: phosphorus ratio), covarying decreases in relative nitrogen:phosphorus supply (Downing and McCauley 1992, Downing 1997, Hall et al. 2005) could also yield more phosphorus-rich producers due to nitrogen-limitation (Goldman et al. 1979, Klausmeier et al. 2004b, Hall et al. 2005). Nitrogen-limited producers typically can store phosphorus to excess, and this effect should elevate phosphorus content of algae. Nonetheless, both of these physiological mechanisms involving light and/or nitrogen:phosphorus ratios imply that the bottom-up, external resource supply to aquatic ecosystems primarily "regulates trophic energy transfer at the base of pelagic food webs due to effects on the stoichiometry of plantherbivore interactions" (Sterner and Elser 2002:305). An extreme interpretation, then, is that grazers essentially eat food of stoichiometric quality served to them by their environment.

However, we will argue that such a bottom-up view of the light: nutrient hypothesis remains incomplete and should be synthesized with grazing. Grazing also can modify the elemental stoichiometry of primary producers growing along light:nutrient gradients. Much empirical (Sommer 1992, Sterner et al. 1998, Elser et al. 2000, Hillebrand and Kahlert 2001, Urabe et al. 2002a, b, Kunz and Diehl 2003, Hall et al. 2004, 2006, Hillebrand et al. 2004) and theoretical (Loladze et al. 2000, 2004, Hall 2004, Hall et al. 2006) work indicated that high rates of herbivory frequently correlated with a lower C:P content in producers (but not always: Sommer et al. 2003). Grazing can directly and indirectly influence producer stoichiometry via three major topdown and bottom-up pathways. First, herbivory can reduce the standing stock of producers, which in turn should increase the instantaneous per capita availability of both nutrients and light to producer organisms. Second, herbivores regenerate nutrients through excretion (Sterner 1986, Elser and Urabe 1999, Vanni 2002), even if they resupply nutrients at different ratios than ingested in their food supply (Sterner 1990, Andersen 1997, Elser and Urabe 1999). Recycling should increase nutrient availability and thus potentially improve elemental food quality. Third, higher mortality rate imposed upon edible algae by grazers will elevate per capita growth rate of producers, and faster turnover tends to increase nutrient content of producers (Droop 1968, Grover 1997). Furthermore, grazer-mediated shifts in species composition (Leibold 1996, Grover 1997) might also alter stoichiometric response of producers that vary in pertinent stoichiometric traits (Andersen 1997), although this possibility has received considerably less attention. Thus, it makes sense that grazers might not merely eat what their ecosystems serve them, but should directly and indirectly shape elemental quality of their food to some degree along gradients of light : nutrient supply.

We elaborate upon N:P supply and grazing arguments here by combining several lines of observational, experimental, and theoretical evidence. As predicted by the light:nutrient hypothesis (Sterner et al. 1997, Sterner and Elser 2002), we observed a positive correlation between light:phosphorus supply ratios and carbon: phosphorus content of edible algal seston from 44 shallow Michigan ponds. However, we also found that lower $\mathrm{N}: \mathrm{P}$ ratios and higher zooplankton grazer biomass corresponded with a higher phosphorus content of algae. A mesocosm experiment that controlled N:P supply ratios and presence of crustacean grazers and an accompanying model revealed that the $\mathrm{N}: \mathrm{P}$ signal from the pond data was likely spurious, but that the presence of grazing was a crucial component of the resource supply-algal stoichiometry relationship. Additionally, we found that changes in species composition varied with stoichiometry of the entire algal assemblage, particularly in the presence of grazers. These results suggest that the pattern behind the light: nutrient hypothesis stems from the net outcome of interactions between bottom-up (resource supply, nutrient recycling) and top-down (grazing) forces operating in these systems.

\section{Methods \\ Pond survey}

During the summer of 2000 , we characterized the light-nutrient environment, seston stoichiometry, and zooplankton biomass in 44 ponds. All sites were located in southwestern Michigan (USA), either proximate to the Kellogg Biological Station's Experimental Pond Facility, Bird Sanctuary, and Lux Arbor Preserve (Kalamazoo and Barry Counties), within Barry and Middleville State Game Areas (Barry County), or within Ludington State Park (Mason County). These small ponds (median surface area, $680 \mathrm{~m}^{2}$; range, 56$17500 \mathrm{~m}^{2}$; median depth, $0.35 \mathrm{~m}$; range, $0.05-2.0 \mathrm{~m}$ ) experienced wide supply gradients of light and nutrients. We approximated incident light supply at the pond surface by estimating the degree of openness of the forest canopy. Images of forest canopy were shot at three locations along the long axis of each pond with a 
digital camera equipped with a hemispherical lens. We analyzed each image using GLA 2.0 software (Frazer et al. 1999), and then averaged canopy cover data for each pond prior to analysis. We also visually estimated macrophyte surface cover by duckweeds (Lemna sp., Wolffia sp.), which reduced subsurface light in these ponds. Duckweed cover was highly variable among ponds. Because the majority of these ponds had either $<20 \%$ or $>80 \%$ areal cover, we grouped ponds in some analyses categorically as containing either less than, or more than, $50 \%$ cover.

To estimate nutrient concentrations, we collected a composite, 8.5-L sample pooled from at least four different sites in each pond. Samples were kept on ice until we returned to the laboratory. Total phosphorus was measured using the molybdate-ascorbic acid method (APHA 1980, Prepas and Rigler 1982), whereas total nitrogen was analyzed using second-derivative UV spectroscopy (Crumpton et al. 1992, Bachmann and Canfield 1996). To measure the carbon:phosphorus $(\mathrm{C}: \mathrm{P}, \mathrm{mg} \mathrm{C} / \mathrm{mg} \mathrm{P}$ ) content of seston (algae + detritus + bacteria), which we equate with algal $C: P$ ratio, we sieved samples through $35-\mu \mathrm{m}$ Nitex screening (Cottingham 1999) and filtered two samples onto pre-combusted, sulfuric-acid cleaned GF/F filters. We waved these filters in sulfuric-acid fumes to remove inorganic carbonates prior to drying them to constant mass at $60^{\circ} \mathrm{C}$. Dried filters were packed into tins (Costech Analytical Technologies, Valencia, California, USA) and were combusted in a Carlo-Erba CHN autoanalyzer (CarloErba, Milan, Italy). Samples for the analysis of particulate $\mathrm{P}(\mathrm{PP})$ were frozen at $-80^{\circ} \mathrm{C}$ and later wet digested for two hours in persulfate. The digestate was filtered through a $1-\mu \mathrm{m}$ pore syringe filter and analyzed for $\mathrm{P}$ content using the molybdate-ascorbic acid method (APHA 1980, Prepas and Rigler 1982). To estimate zooplankton biomass, we preserved a second, 32-L sample in acid Lugol's solution, identified all crustaceans to genus or species level (Pennak 1978), and estimated dry mass using published length-mass relationships (McCauley 1984).

\section{Field mesocosm experiment}

In this experiment, we manipulated four factors: light (shaded or unshaded), nutrient supply rate (high and low), nutrient ratios (three $\mathrm{N}: \mathrm{P}$ ratios), and grazer composition (manipulating presence or absence of crustacean zooplankton grazers; see also Hall et al. 2004, 2005, 2006). These 24 treatment combinations were replicated three times each and in $720.3-\mathrm{m}^{3}$ plastic cattle tanks covered with fiberglass window screen lids. During May-June 2000, we created gradients of light supply in one-half of these tanks by pinning $90 \%$ shade cloth onto their lids. To each tank, we added $\sim 2 \mathrm{~cm}$ of a silica sand bottom substrate, well water, and inorganic nitrogen ( $\mathrm{N}$, as $\mathrm{NaNO}_{3}$ ) and phosphorus ( $\mathrm{P}$, as $\mathrm{NaH}_{2} \mathrm{PO}_{4}$ ) sufficient to alter nutrient concentrations in the well water to obtain three target N:P ratios (nutrient ratio treatment, $5: 1,14: 1$, and $50: 1$ by mass). Two different supply rates (nutrient supply level treatment, low and high) were applied. For the low nutrient supply rate, the targeted TN (total nitrogen) and TP (total phosphorus) concentrations in the tank water were 700 and $14,370.4$ and 26.5 , and 221.4 and $44.3 \mathrm{mg} / \mathrm{m}^{3}$, respectively. The high nutrient supply rate was 10 times higher than the low nutrient supply. (Interested readers can observe actual concentrations of TP measured at the end of the experiment in Appendix A.)

We then inoculated all of the tank mesocosms fortnightly with diverse assemblages of natural phytoplankton taken from the wide, natural light-nutrient gradients provided by subsets of the Michigan ponds described previously (see Pond survey). Once collected, the entire pooled phytoplankton assemblage was bubbled with gaseous $\mathrm{CO}_{2}$, and the liquid was then filtered twice through a $35-\mu \mathrm{m}$ mesh to remove crustacean zooplankton. A small inoculum of filtered algae was then added to all tanks. Similarly, diverse assemblages of crustacean zooplankton from ponds were pooled and concentrated using a $153-\mu \mathrm{m}$ mesh net; a small inoculum of these zooplankton was then added to cattle tanks in treatments receiving crustacean grazers. Because we did not count micro-zooplanton (ciliates and rotifers), we cannot ensure that treatments that did not receive crustacean zooplankton did not experience any grazing. Hence, the two grazer composition treatments are categorized as containing or not containing crustacean grazers. However, all mesocosms received 30 Physa spp. snails and 30 Rana catesbeana tadpoles to graze and remineralize nutrients bound in benthic algae. After imposing the light-nutrient-grazing manipulations, we continued to add small weekly $\mathrm{N}$ and $\mathrm{P}$ supplements designed to offset an estimated $5 \%$ per day loss rate of nutrients from the water column (M. A. Leibold and V. H. Smith, unpublished data).

After 12 weeks of inoculations and biotic interactions, we characterized the resulting light: nutrient environment, seston stoichiometry, and algal community structure on 15-17 September. We collected water subsamples from each tank using PVC pipe samplers, and measured total nitrogen and total phosphorus content of the whole water and the carbon : phosphorus content of seston, using methods described previously (see Pond survey). We also measured light extinction in each tank with a spherical light sensor (LI-193; LI-COR, Lincoln, Nebraska, USA) and using formulas presented in Appendix A. Finally, we preserved water samples containing phytoplankton in $0.25-0.50 \%$ glutaraldehyde for later enumeration to genera or species by Phycotech (St. Joseph, Michigan, USA). Here, we only present data on the relative biovolume pooled into three dominant taxonomic categories (greens, Division Chlorophyta; cyanobacteria, Cyanophyta; diatoms, Chromophyta; see Appendix A for details on biovolume calculations). Grouping of algal taxa at the divisional level seems coarse at first glance but has proved effective in previous 
studies (e.g., Cottingham and Carpenter 1998, Cottingham et al. 1998). These counts did not include floating mats of the green alga Oedogonium, which we have described elsewhere (Hall et al. 2006).

\section{Statistical methods}

We characterized relationships between light-nutrient supply and seston stoichiometry in both pond survey and experimental mesocosm data sets using correlation and linear regression based on ordinary least squares. Statistical significance of correlation coefficients was found using 9999 randomizations of $\log _{10}$-transformed data (Legendre and Legendre 1998). These randomizations used the distribution of data themselves rather than assumed theoretical distributions to test for significance. However, the results produced by these randomizations closely resembled those yielded from more traditional tables. Furthermore, the log transformations were used to linearize relationships. For those relationships involving ratios with shared terms (TN:TP vs. TP) or part-whole relationships (seston C:P vs. light: $\mathrm{TP}$, in which seston $\mathrm{P}$ is a fraction of TP), we also calculated conservative tests, which accounted for possible "spurious" correlations (as explained and presented in Appendix A). As a complementary level of analysis, we bootstrapped bias-corrected, 95\% confidence intervals around each parameter estimated by regression models by resampling the data (10000 times, following Dixon 2001). These regression models provided estimates of slopes and intercepts that could be used for comparison with other studies.

\section{Model}

To help us understand the empirical and experimental data, we examined the behavior of a simple, stoichiometrically explicit model that captured the key elements of the light: nutrient hypothesis (Fig. 1). That is, this chemostat-style model allowed variation in supply of nitrogen and phosphorus to the system, stoichiometric plasticity of the producers, extinction of light with depth, and nutrient- or carbon-limited grazing. Because we presented the model in detail in Appendix B, we only summarized its key features here. It was a generic variation on models that have been previously published by us (Hall 2004, Hall et al. 2005, 2006) and by others (Andersen 1997, Hessen and Bjerkeng 1997, Klausmeier et al. 2004b). The model included dynamically variable nitrogen : carbon and phosphorus : carbon content (quota) of an edible alga. (Note that we follow convention by modeling quota as nutrient:carbon ratio but show results from the model as carbon: nutrient ratios to better match with presented data.) Following the Droop-variable stores formulation (Droop 1968, Grover 1997), change in quota depended on the balance of gains from uptake of freely available nutrient and losses from "dilution by growth." The net result captures storage of nutrient by the producers. Per capita production of the algae then depended upon this storage of nutrient, but

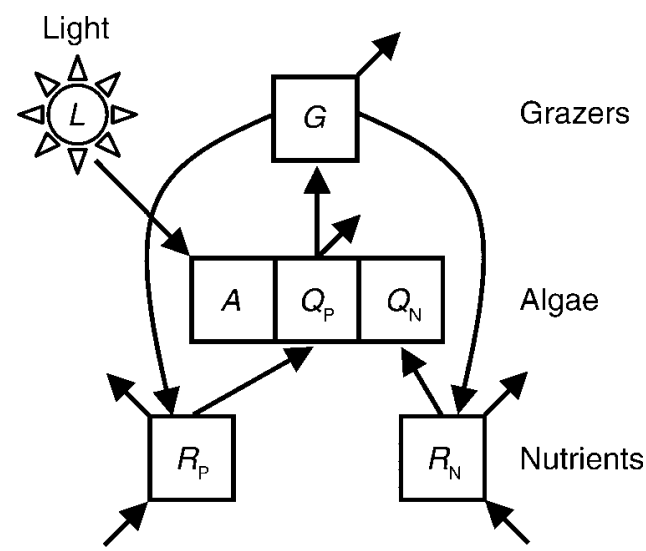

FIG. 1. Flow diagram of a stoichiometrically explicit, chemostat model of a food chain. Production of algal biomass, $A$, depends upon light, $L$, and uptake from pools of freely available nitrogen, $R_{\mathrm{N}}$, and phosphorus, $R_{\mathrm{P}}$, which are first stored internally (as quota $Q_{\mathrm{N}}$ and $Q_{\mathrm{P}}$ ) and then used for growth according to the Droop-variable stores kinetics. Grazers, $G$, consume algae, but production of new biomass of grazers (and recycling of nutrients back to available pools following grazing) depends upon the degree of elemental mismatch between stoichiometry of grazer tissue and that of algae. Nutrients contained in dead algae and grazers are instantly recycled back into freely available pools, and nutrients are supplied to the system at a constant rate. Finally, nutrients, algae, and grazers are lost from the system at a constant rate.

was limited by one nutrient at a time (assuming Leibig's Law of the Minimum; Rhee 1978, Tilman 1982). Production of the algae also depended multiplicatively upon light supply, which was extinguished with depth due to absorption of light by algae and by background sources (following Huisman and Weissing 1995, Hall et al. 2006, Passarge et al. 2006). These producers were consumed by grazers according to a linear functional response (Hall 2004). While a saturating functional response would have seemed more realistic for zooplankton grazers (Sarnelle 2003), this linear response helped us avoid the exotic, nonlinear behaviors exhibited by some related stoichiometric food chain models (i.e., deterministic extinction of grazers through homoclininc catastrophes; Andersen 1997, Loladze et al. 2000, Muller et al. 2001). Production of grazers (and the total amount and ratios of nutrients that grazers recycle) depended upon the degree of mismatch in the static nutrient:carbon stoichiometry of grazers vs. the dynamic stoichiometry (quota) of algae. The system was open to input of nutrients supplied at differing ratios from the environment, and to losses of nutrients, grazers, and algae. Finally, nutrients contained in tissues of dead algae and grazers were recycled instantaneously.

We considered the equilibrial behavior of this model with and without a Daphnia-like grazer. The no-grazer case provides an extreme analogue to treatments of the mesocosm experiment that did not receive crustacean grazers. This case was extreme because phytoplankton in environments without crustacean grazers could have 

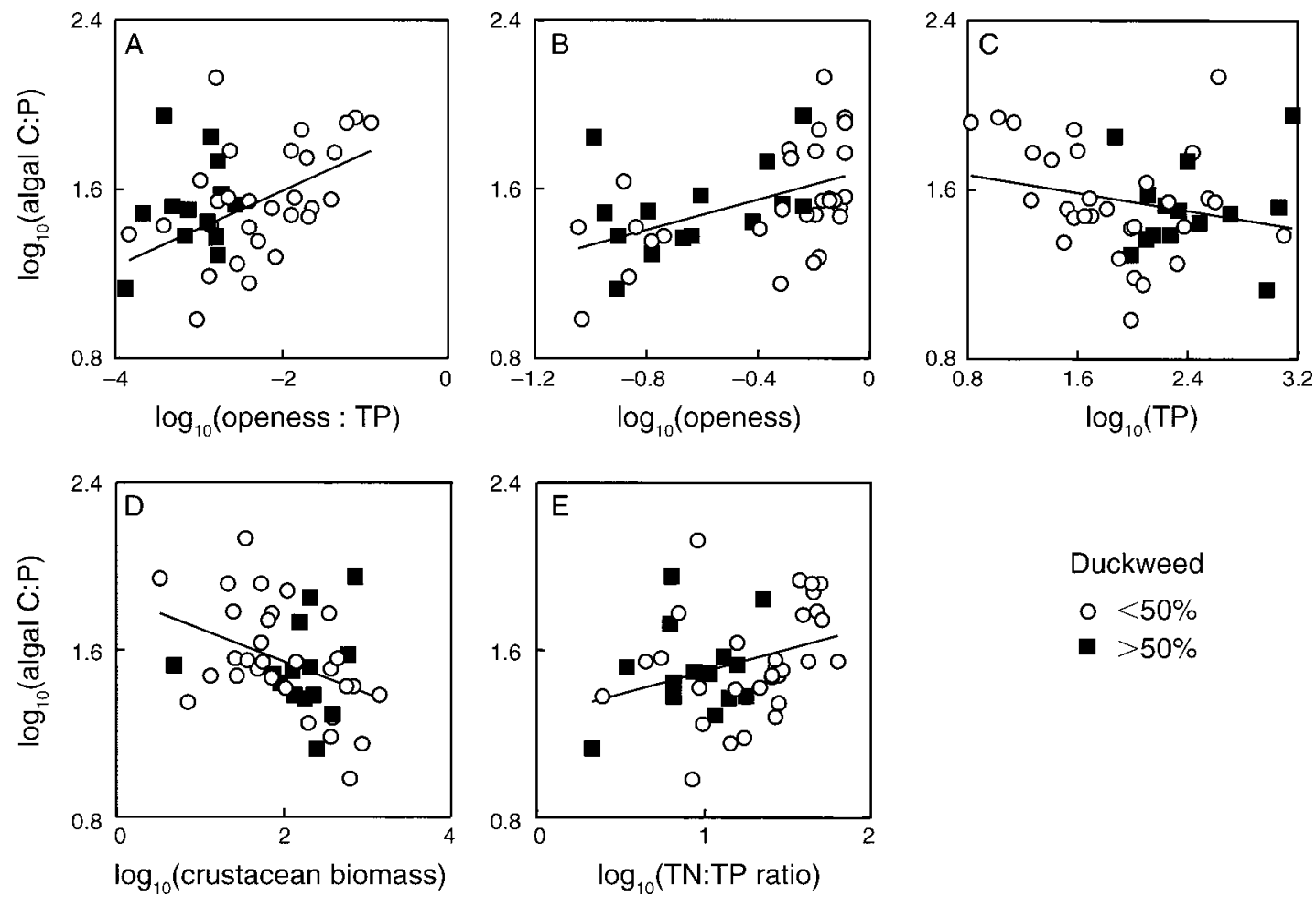

Duckweed
$0<50 \%$
- $>50 \%$

FIG. 2. Relationships between light (canopy openness) and nutrient supply and the carbon:phosphorus (C:P; $\mathrm{mg} \mathrm{C} / \mathrm{mg} \mathrm{P})$ content of algal seston collected in ponds. Ponds with $>50 \%$ duckweed cover are noted as solid squares. Seston C:P in ponds increased with (A) the ratio of canopy openness (dimensionless) to total phosphorus (TP; $\mathrm{mg} \mathrm{P} / \mathrm{m}^{3}$ ) and (B) canopy openness, but (C) decreased with TP. However, (D) C:P content of algae also decreased with biomass of crustacean grazers $\left(\mathrm{g}\right.$ dry biomass $\left./ \mathrm{m}^{3}\right)$ and (E) increased with total nitrogen : total phosphorus (TN:TP; $\mathrm{mg} \mathrm{N} / \mathrm{mg} \mathrm{P}$ ) ratio, an index of N:P supply.

received herbivory from micrograzers (e.g., ciliates and rotifers). Despite that limitation, the comparison between response of algal stoichiometry to no grazers and a Daphnia-like grazer still proved useful here.

\section{Results}

\section{Pond survey}

As in lake ecosystems (Sterner et al. 1997), we observed a positive relationship between an index of light: nutrient supply (canopy openness:TP) and the carbon: phosphorus (C:P) content of edible algal seston $(r=0.40, P=0.0080$; Fig. 2A; Appendix A: Table A1). Thus, ponds with low light supply relative to nutrient supply produced more nutrient-rich algal seston for crustacean zooplankton grazers. The numerator of this light: nutrient index is canopy openness, the fraction of incident light supply that was not blocked by surrounding forest canopy. This openness index ranged from heavy shading $(<0.10)$ to virtually no shading $(>0.85$; Fig. 2B). Canopy openness correlated more strongly with $\mathrm{C}: \mathrm{P}(r=0.48, P=0.0009$; Fig. $2 \mathrm{D})$ than did the denominator, total phosphorus (TP; $r=-0.24, P=0.12$; Fig. 2C; Appendix A: Table A1).

However, two factors confounded this relationship between resource supply and producer stoichiometry in these ponds. First, ponds with higher crustacean grazer biomass tended to produce seston with lower C:P ratios $(r=-0.35, P=0.023$ in all ponds; Fig. 2D; Appendix A: Table A1). Second, seston C:P content also increased with an index of the relative supply of nitrogen:phosphorus to these ponds, TN:TP ratio $(r=0.32, P=$ 0.0320; Fig. 2E, Appendix A: Table A1). Interpretation of these additional relationships is difficult because each potential factor covaried with other factors. For instance, both crustacean zooplankton biomass and water column TN:TP ratio covaried with total phosphorus $(r=0.54, P=0.0001 ; r=-0.85, P<0.0001$, respectively), canopy openness ( $r=0.38, P=0.0099 ; r=$ $0.36, P=0.016$, respectively), and the canopy: phosphorus index $(r=-0.58, P<0.0001 ; r=0.81, P<$ 0.0001, respectively; see also Appendix A: Table A2). Furthermore, grazer biomass and TN:TP ratio were negatively correlated themselves $(r=-0.49, P=0.0003$; Appendix A: Table A2). Given these intercorrelations, it is difficult to interpret these patterns without experimental evaluation of grazing by crustaceans and variation in $\mathrm{N}: \mathrm{P}$ supply.

Experiment and model: importance of crustacean grazing, not N:P supply

Both the mesocosm experiment and model confirmed that grazing by crustaceans was a key component of the 


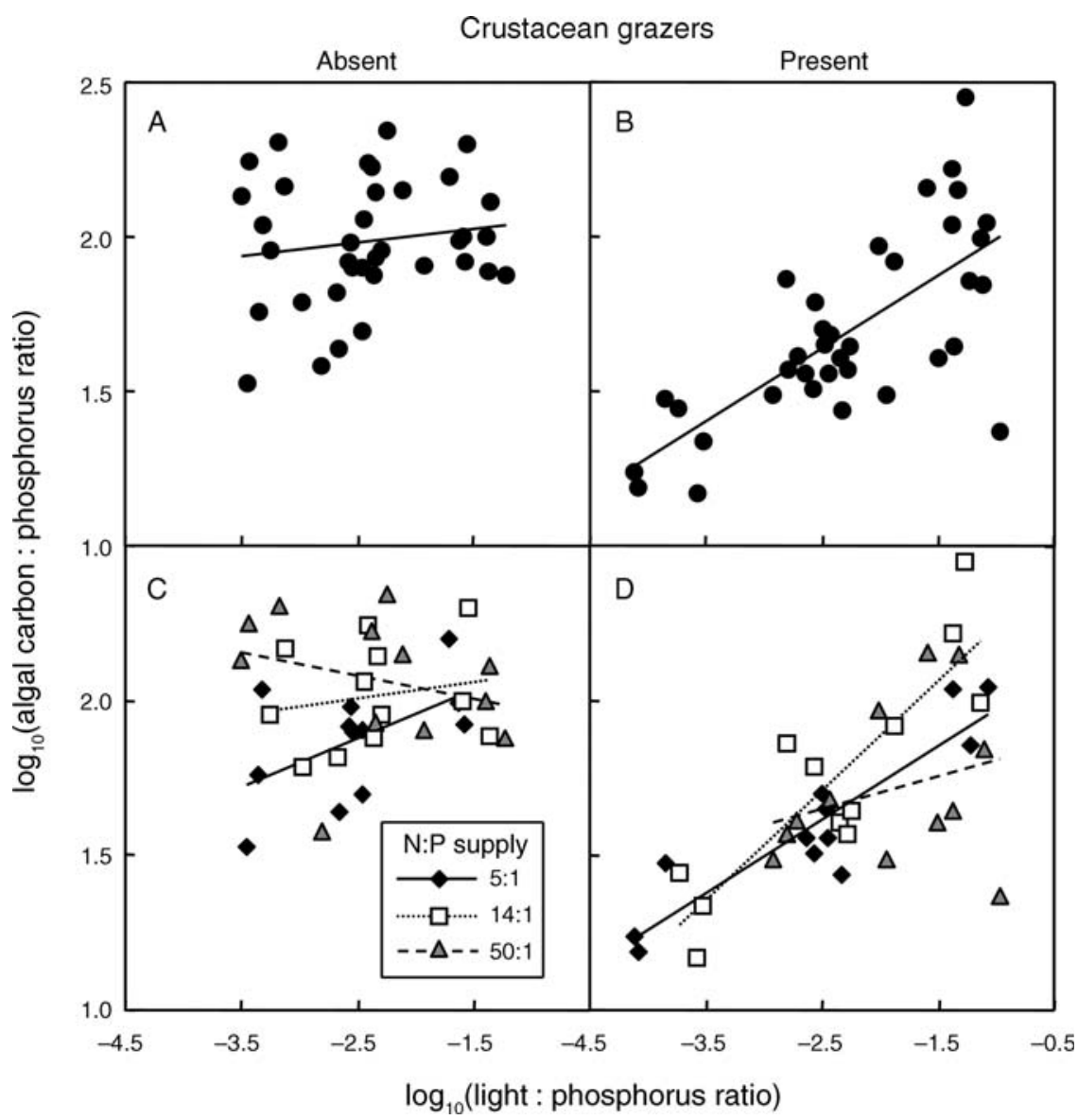

FIG. 3. Experimental examination of the light: nutrient hypothesis in mesocosms: response of sestonic carbon:phosphorus ratios $(\mathrm{mg} \mathrm{C} / \mathrm{mg} \mathrm{P})$ to the ratio of light: nutrients $\left(\mathrm{m}^{3} / \mathrm{mg} \mathrm{P}\right)$ supplied to systems containing or not containing crustacean zooplankton. (A, B) All treatments combined, where lines are best-fitting linear regression models. (C, D) Separate relationships shown for the three different nitrogen: phosphorus ratio treatments.

resource supply-producer stoichiometry pattern in these shallow systems. In tanks without crustacean grazers, we found no relationship between the modified index of light : nutrient supply, $\hat{I}_{\mathrm{M}} / \mathrm{TP}$, and algal carbon:phosphorus (C:P) ratio $(r=0.14, P=0.41$; Fig. $3 \mathrm{~A}$; Appendix A: Table A3). Thus, light : nutrient supply alone did not drive predictable variation in algal $\mathrm{C}: \mathrm{P}$ content. In contrast, systems containing crustacean grazers showed the positive relationship between the light:nutrient supply ratio and seston $\mathrm{C}: \mathrm{P}$ content predicted by the light: nutrient hypothesis $(r=0.80, P<0.0001$; Fig. 3B), but here the pattern emerged due to variation in both resource supplies and to the presence of crustacean grazers.

The grazing effect of crustacean zooplankton on algal $\mathrm{C}: \mathrm{P}$ content was also manifested in interactions between resource supply and grazing treatments (Appendix A: Table A4, Fig. A1), and was readily explained by the food chain model. This model predicted that, without any grazing, algal C:P content of algae in these shallow systems should remain fairly flat until light supply declined to very low levels (Fig. 4). In contrast, in the presence of grazers, C:P dropped much more substantially with light: phosphorus ratio in an S-shaped curve (Fig. 4). The orientation and size of this drop with light: phosphorus ratio depended upon the intensity of the incident light supply (Fig. 4).

While highlighting a critical role for grazing by crustacean grazers, neither the mesocosms nor the model revealed a major role for nitrogen: phosphorus supply ratios in shaping C:P stoichiometry along the light : phosphorus gradients. In mesocosms without crustacean grazers, we found a positive relationship between light : nutrient supply and seston C:P content within the $5: 1 \mathrm{~N}: \mathrm{P}$ treatments $(r=0.54, P=0.078)$, but no relationship at $14: 1 \mathrm{~N}: \mathrm{P}(r=0.20, P=0.54)$ or in the $50: 1 \mathrm{~N}: \mathrm{P}$ treatments $(r=-0.20, P=0.52$; Fig. 3C; Appendix A, Table A3). The model supported this result; it predicted a flat response to light: TP supply at very different N:P ratios, such as 50:1 and 5:1 (Fig. 4). In mesocosms grazed by crustaceans, we found strong positive relationships between C:P ratio and light: nutrient supply at 5:1 and $14: 1$ treatments $(r=0.91, P=0.0004$; and $r=0.86, P=$ 0.0006, respectively; Fig. 3D), and a weaker (and 


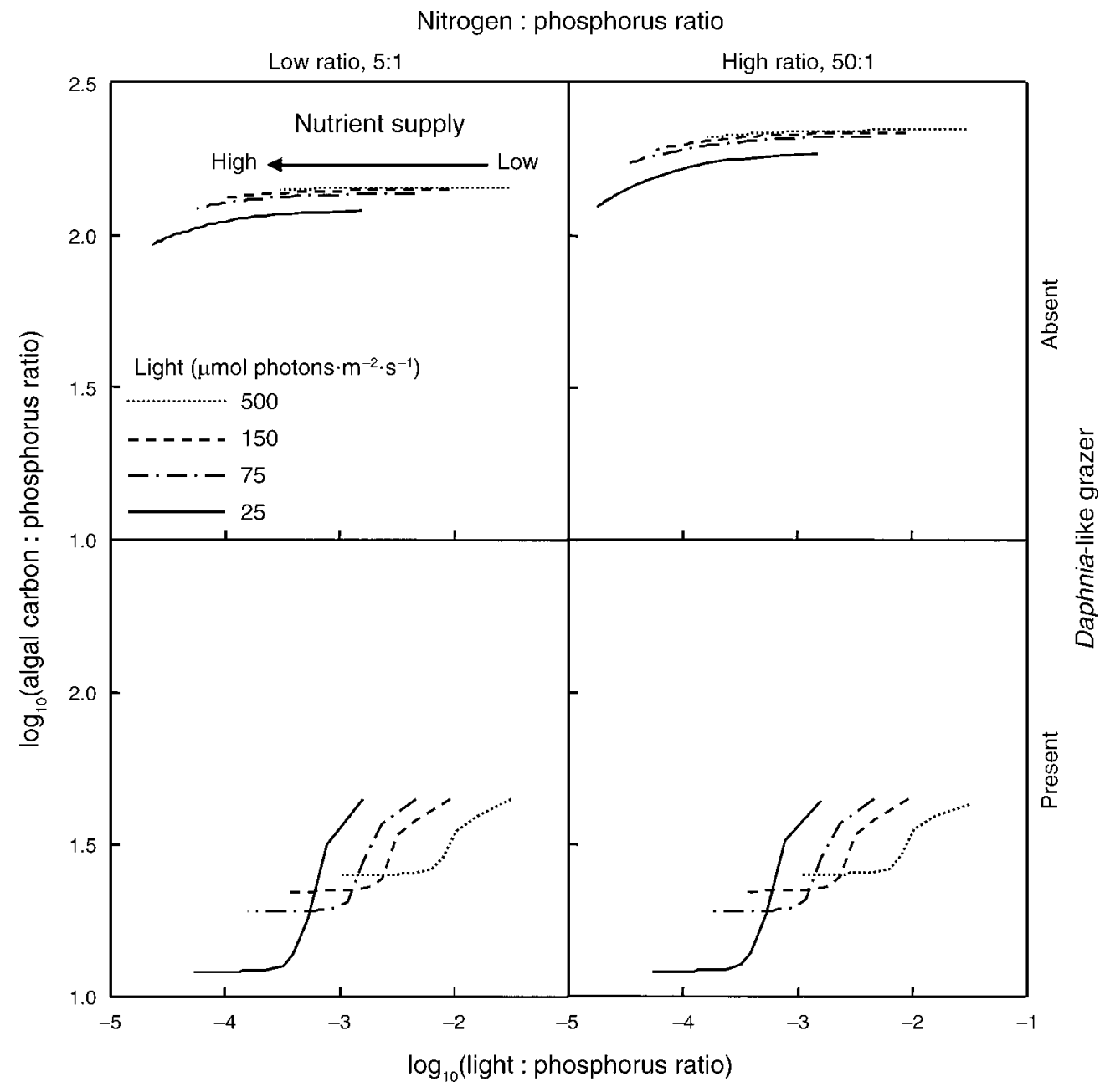

FIG. 4. Response of a stoichiometrically explicit food chain model to light : nutrient gradients. In systems without Daphnia-like grazers, carbon : phosphorus stoichiometry $(\mu \mathrm{g} \mathrm{C} / \mu \mathrm{g} \mathrm{P})$ of algae changed little over broad light: phosphorus gradients, despite large gradients of incident light supply (from 25 to $500 \mu \mathrm{mol}$ photons $\cdot \mathrm{m}^{-2} \cdot \mathrm{s}^{-1}$ ). (Lines connect nutrient supply from 10 to $300 \mathrm{mg} \mathrm{P} / \mathrm{m}^{3}$, moving right to left.) Instead, lower N:P supply (5:1) produces algae with a lower overall C:P ratio than systems receiving higher $\mathrm{N}: \mathrm{P}$ supply (50:1). The presence of grazers lowers algal C:P ratio overall, but also yields " $\mathrm{S}$ "-shaped curves in which C:P drops to lower levels as nutrient enrichment increases, light supply decreases, and light: phosphorus ratios drop. With grazing, effects of different N:P ratios become subtle.

shallower) one at $50: 1 \mathrm{~N}: \mathrm{P}(r=0.54, P=0.083$; Appendix A: Table A3). The model did not explain such behavior at the 50:1 ratio because it forecasted that N:P supply should matter little for the light: nutrient hypothesis in the presence of herbivory (Fig. 4). One possible explanation involves different patterns of phosphorus allocation in 50:1 than in 14:1 and 5:1 environments of the experiment (Appendix A: Table A4, Fig. A2). These patterns involved complex interactions. Generally, in environments receiving $\mathrm{N}: \mathrm{P}$ at a 50:1 ratio, TP was higher in the absence of crustacean grazers. Meanwhile, TP in crustacean-grazed, 14:1 and 5:1 N:P environments exceeded that in ones without crustacean grazers. Although these results involving TP seemed interesting, our simple food chain model lacked mechanisms to anticipate them.

\section{Experiment: compositional shifts of phytoplankton}

Algal community structure at the division level of greens (Chlorophyta), cyanobacteria (Cyanophyta), and diatoms (Chromophyta) shifted along the experimental resource supply and grazing gradients. These shifts of species appeared among nutrient ratio treatments and in interactions with grazer and resource supply (which we detail in Appendix A: Table A4, Fig. A3). A key point here is that shifts seen in these light $\times$ grazer composition and nutrient supply $\times$ grazer composition interactions also correlated with stoichiometry of the entire algal assemblage. For instance, C:P content of assemblages dropped as biovolume of diatoms increased in shaded treatments (with or without crustacean grazers; Fig. 5A), and it dropped at high and low nutrient supply with grazing by crustaceans (but not in 
the absence of these grazers; Fig. 5B). Combined biovolume of cyanobacteria and greens responded oppositely as diatoms in these interactions, producing positive correlations with C:P ratios (Fig. 4A, B). However, when viewed separately, we found only weak correlations between $\mathrm{C}: \mathrm{P}$ ratio of entire algal assemblages and relative abundance of greens and of cyanobacteria (not shown).

\section{Discussion}

The stoichiometric light: nutrient hypothesis (Sterner et al. 1997) links the supplies of two key resources, light and phosphorus, with elemental content of primary producers. This hypothesis predicts that systems with high supply of light relative to phosphorus should yield phosphorus-poor cells of primary producers, while systems with lower supply of light relative to phosphorus should yield phosphorus-rich producers. This variation in elemental food quality may then shape transfer of energy and nutrients among trophic levels. The pattern on which the hypothesis is based emerged from lake ecosystems, where light supply is determined largely by extinction with depth (Sterner et al. 1997, Diehl et al. 2002, 2005). Here, we saw this relationship in small, shallow forest ponds, where light supply was governed by degree of shading from surrounding forest canopy. Thus, our results broadened application of the light: nutrient hypothesis to lotic systems ranging from tiny, forested ponds to Laurentian Great Lakes (Sterner et al. 1997, Sterner and Elser 2002).

While this extension is useful, our main objective here was to expand a largely bottom-up interpretation of the light: nutrient hypothesis. Typical discussion of this hypothesis stresses physiological links between resource supply, light limitation, and luxury consumption and storage of phosphorus (Sterner et al. 1997, Hessen et al. 2002, Sterner and Elser 2002). These links seem perfectly reasonable (Healey 1985, Urabe and Sterner 1996, Hessen et al. 2002), but imply that resource supplies to ecosystems mainly determine elemental food quality for grazers. Our experimental and theoretical results with shallow systems instead revealed that crustacean herbivores did not merely receive food quality served to them by their environment; instead, the positive correlation between light: phosphorus supply and algal C:P stoichiometry predicted by the LNH only emerged in mesocosms grazed by crustaceans. Mesocosms without herbivory by crustaceans exhibited a flat response of algal C:P content with light: nutrient ratio, despite very broad gradients of nutrient, light, and relative light: nutrient supply.

Two mechanisms almost certainly linked grazers to the resource supply-stoichiometry pattern. First, grazers generally increase per capita nutrient availability for producers by reducing density of producers, they recycle nutrients, and they enhance per capita turnover rate of their prey (Sterner 1986, Elser and Urabe 1999, Vanni 2002). Thus, our results suggested that the light: nutrient
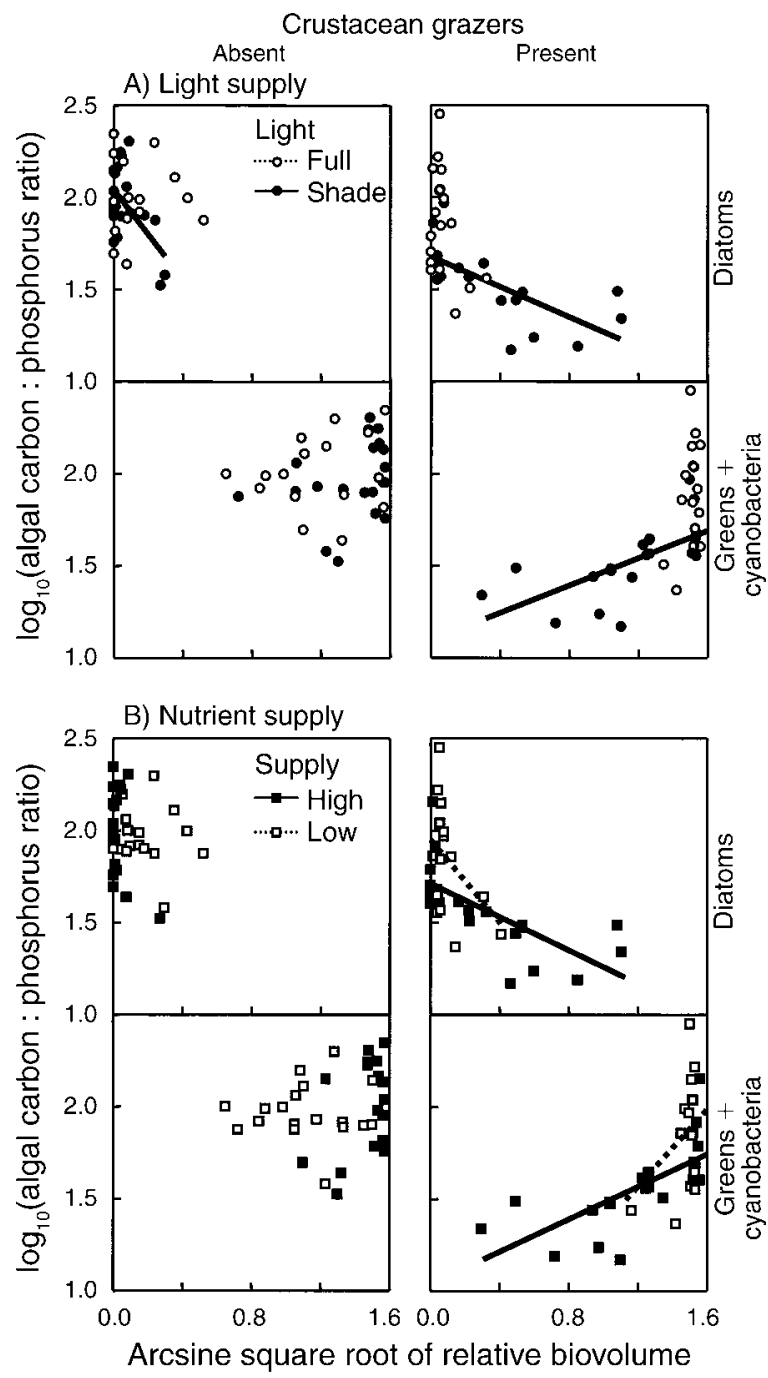

FIG. 5. Correlations between relative biovolume (arcsine square-root transformed) of three broad taxonomic groupings of algae (diatoms, Chromophyta; greens, Chlorophyta + cyanobacteria, Cyanophyta) and the carbon: phosphorus stoichiometry (mg C/mg P) of entire algal assemblages. Related regression lines serve only to illustrate relationships here (significant at the $\alpha=0.05$ level). We investigated these particular relationships following examination of interactions between the grazer composition treatment and (A) light or (B) nutrient supply treatments. (See Appendix A for details.)

hypothesis' resource supply-producer stoichiometry pattern reflects interplay of top-down (biomass removal) and bottom-up (resource supply, recycling) pathways. Second, grazers altered community composition of primary producers. This latter result complements the idea that food web processes, such as competition among grazers, interactions with inedible producers, and predation on grazers can all potentially shape algal stoichiometry (Hall 2004, Hall et al. 2004, 2005, 2006; S. R. Hall, J. B. Shurin, R. M. Nisbet, and S. Diehl, unpublished manuscript).

We do not wish to claim here that bottom-up processes have no role in shaping the correlation behind 
the light: nutrient hypothesis, of course. In fact, the characteristic positive correlation between light: phosphorus supply and algal C:P ratio emerged in Diehl et al.'s reduced-grazing enclosures that varied in mixing depth due to self-shading by algae, a result that our food chain model readily anticipated (Appendix C; Diehl et al. 2002, 2005). However, we show that the slope of the resource supply-seston stoichiometry relationship from Diehl et al.'s $(2002,2005)$ enclosures was shallower than that from natural lakes surveyed by Sterner et al. (1997; Appendix C). Natural lakes, of course, contain crustacean grazers, and the model predicted that grazing should steepen the resource supply-seston stoichiometry slope, even along gradients of mixing depth (Appendix C). Consequently, these findings from lakes (Sterner et al. 1997) and the lake enclosure experiments (Diehl et al. 2002, 2005), when combined with our data from shallow ponds, emphasized that grazing by crustaceans may provide a critical component of the light: nutrient hypothesis in a variety of systems, from shallow to deep.

The experiment and model also clarified the role which another bottom-up process, supply of nitrogen relative to phosphorus, might play in producing the light: nutrient hypothesis' pattern. A priori, one might suspect that N:P supply confounds the light: nutrient hypothesis because $\mathrm{N}: \mathrm{P}$ ratios negatively covary with total nutrient supply in aquatic ecosystems ranging from ponds to oceans (Downing and McCauley 1992, Downing 1997, Hall et al. 2005), and algal C:P ratios can decrease in systems with nutrients supplied at low $\mathrm{N}: \mathrm{P}$ ratios (Goldman et al. 1979, Sterner and Elser 2002). Combined, these two pieces of information suggest that the light: nutrient hypothesis might be driven, at least in part, by covariation in environmental $\mathrm{N}: \mathrm{P}$ supply. Indeed, we found covariance between algal $\mathrm{C}: \mathrm{P}$ ratio and with $\mathrm{N}: \mathrm{P}$ supply ratio in natural ponds. However, our results indicated that this N:P supplyalgal stoichiometry pattern reflected correlation with $\mathrm{P}$ enrichment, but not likely causation. This result emerged after experimentally breaking apart natural covariation between $\mathrm{P}$ enrichment and N:P supply. Both theoretical predictions and experimental data qualitatively showed that N:P ratios probably did not drive the resource supply-stoichiometry pattern in pond systems grazed by crustaceans.

That being said, N:P supply, light supply, nutrient enrichment, and grazing promoted shifts in composition of algal species of the experiment, detectable even at the division level. Such shifts in algal composition along these gradients are anticipated by much prior experimental and theoretical work (Tilman 1982, Smith 1983, 1986, Leibold 1996, Grover 1997, Gragnani et al. 1999, Passarge et al. 2006). A key point here is that these shifts in algal composition correlated with variation in carbon: phosphorus content of the entire algal assemblage in some circumstances. These taxa-stoichiometry correlations matter for two reasons. First, producer species often vary in physiological traits that influence their stoichiometry (Tilman et al. 1986, Andersen 1997, Klausmeier et al. 2004a). It is quite possible that differences in species traits may cause some variation around resource supply-producer stoichiometry relationships or may influence its slope. However, links between species composition of phytoplankton and the light: nutrient hypothesis remain largely unexplored. Additionally, algal species vary in edibility (Andersen 1997, Hall et al. 2006), although we did not characterize assemblages according to their edibility here. Indigestible algae may have very high C:P contents yet yield carbon, not nutrient limitation, because of the refractory nature of the organic molecules composing these species (DeMott and Tessier 2002, Tessier and Woodruff 2002). Therefore, translation of variation in seston $\mathrm{C}: \mathrm{P}$ content into variation in food quality may depend strongly on shifts in species composition of producers along gradients of resource supply (DeMott and Tessier 2002, Tessier and Woodruff 2002, Hall et al. 2006).

The light: nutrient hypothesis (Sterner et al. 1997) has catalyzed our understanding of important interactions between supplies of resources to ecosystems, food quantity and quality for grazers, and transfer of energy and nutrients among trophic levels. Our aim in this paper is to strengthen this hypothesis and build upon its theoretical foundation. Clearly, the supply of resources to ecosystems shapes producer stoichiometry through direct, bottom-up pathways. However, data from surveys of natural pond systems, a mesocosm experiment, and a stoichiometrically explicit model all suggest that a solely bottom-up perspective did not fully explain links between relative supply of light: phosphorus and the cellular stoichiometry of producers. Instead, these links emerged as the net result of both bottom-up (resource supply, nutrient recycling) and top-down (biomass removal) feedbacks mediated through direct and indirect pathways. Additionally, our results suggest that further development of the light: nutrient hypothesis could integrate changes in species composition of producers over gradients of resource supply (Hall et al. 2006). Such a synthesis should yield more powerful theory for both ecological stoichiometry and community ecology (Moe et al. 2005).

\section{ACKNOWLEDGMENTS}

We thank T. Darcy-Hall, A. Downing, P. Geddes, and $\mathrm{N}$. Howe for help with sampling the cattle tank experiment and natural ponds. We analyzed the C:N samples in the Robertson lab at the W. K. Kellogg Biological Station (KBS) with the help of A. Corbin and T. Darcy-Hall. Thanks also go to G. Mittelbach, N. Consolatti, A. Tessier, and P. Woodruff for technical support. Finally, S. Diehl kindly provided us with data from his experiments. Primary funding came from NSF DEB 98-15799, DEB 02-35579, and funds from Indiana University. This is KBS contribution number 1277 .

Literature Cited

Andersen, T. 1997. Pelagic nutrient cycles: herbivores as sources and sinks. Springer-Verlag, New York, New York, USA. 
APHA. 1980. Standard methods for the examination of water and wastewater. 15th edition. American Public Health Association, Washington, D.C., USA.

Bachmann, R. W., and D. E. Canfield, Jr. 1996. Use of an alternative method for monitoring total nitrogen concentrations in Florida lakes. Hydrobiologia 323:1-8.

Cottingham, K. L. 1999. Nutrients and zooplankton as multiple stressors of phytoplankton communities: evidence from size structure. Limnology and Oceanography 44:810-827.

Cottingham, K. L., and S. R. Carpenter. 1998. Population, community and ecosystem variates as ecological indicators: phytoplankton response to whole-lake enrichment. Ecological Applications 8:508-530.

Cottingham, K. L., S. R. Carpenter, and A. St. Amand. 1998. Responses of epilimnetic phytoplankton to experimental nutrient enrichment in three small seepage lakes. Journal of Plankton Research 20:1889-1914.

Crumpton, W. G., T. M. Isenhart, and P. D. Mitchell. 1992. Nitrate and organic $\mathrm{N}$ analyses with second-derivative spectroscopy. Limnology and Oceanography 37:907-913.

DeMott, W. R., R. D. Gulati, and K. Siewertsen. 1998. Effects of phosphorus-deficient diets on the carbon and phosphorus balance of Daphnia magna. Limnology and Oceanography 43:1147-1161.

DeMott, W. R., and A. J. Tessier. 2002. Stoichiometric constraints vs. algal defenses: testing mechanisms of zooplankton food limitation. Ecology 83:3426-3433.

Diehl, S., S. A. Berger, R. Ptacnik, and A. Wild. 2002. Phytoplankton, light, and nutrients in a gradient of mixing depths: field experiments. Ecology 83:399-411.

Diehl, S., S. A. Berger, and R. Wöhrl. 2005. Flexible nutrient stoichiometry mediates environmental influences on phytoplankton and its abiotic resources. Ecology 86:2931-2945.

Dixon, P. M. 2001. The bootstrap and the jackknife: describing the precision of ecological indices. Pages 267-288 in S. M. Scheiner and J. Gurevitch, editors. Design and analysis of ecological experiments. Oxford University Press, New York, New York, USA.

Downing, J. A. 1997. Marine nitrogen : phosphorus stoichiometry and the global N:P cycle. Biogeochemistry 37:237-252.

Downing, J. A., and E. McCauley. 1992. The nitrogenphosphorus relationship in lakes. Limnology and Oceanography 37:936-945.

Droop, M. R. 1968. Vitamin B12 and marine ecology. IV. The kinetics of uptake, growth, and inhibition in Monochrysis lutheri. Journal of the Marine Biological Association of the United Kingdom 48:689-733.

Elser, J. J., K. Hayakawa, and J. Urabe. 2001. Nutrient limitation reduced food quality for zooplankton: Daphnia response to seston phosphorus enrichment. Ecology 82:898-903.

Elser, J. J., R. W. Sterner, A. E. Galford, T. H. Chrzanowski, D. L. Findlay, K. H. Mills, M. J. Patterson, M. P. Stainton, and D. W. Schindler. 2000. Pelagic C:N:P stoichiometry in a eutrophied lake: responses to a whole-lake food-web manipulation. Ecosystems 3:293-307.

Elser, J. J., and J. Urabe. 1999. The stoichiometry of consumerdriven nutrient recycling: theory, observations, and consequences. Ecology 80:735-751.

Frazer, G. W., C. D. Canham, and K. P. Lertzman. 1999. Gap light analyzer (GLA), version 2.0. Imaging software to extract canopy structure and gap light transmission indices from true-colour fisheye photographs, users manual and program documentation. Simon Fraser University, Burnaby, British Columbia, Canada and the Institute of Ecosystem Studies, Millbrook, New York, USA.

Goldman, J. C., J. J. McCarthy, and D. G. Peavey. 1979. Growth rate influence on the chemical composition of phytoplankton in oceanic waters. Nature 279:210-215.

Gragnani, A., M. Scheffer, and S. Rinaldi. 1999. Top-down control of cyanobacteria: a theoretical analysis. American Naturalist 153:59-72.
Grover, J. P. 1997. Resource competition. Chapman and Hall, New York, New York, USA.

Hall, S. R. 2004. Stoichiometrically-explicit competition between grazers: species replacement, coexistence, and priority effects along resource supply gradients. American Naturalist 164:157-172

Hall, S. R., M. A. Leibold, D. A. Lytle, and V. H. Smith. 2004. Stoichiometry and planktonic grazer composition over gradients of light, nutrients, and predation risk. Ecology 85:2291-2301.

Hall, S. R., M. A. Leibold, D. A. Lytle, and V. H. Smith. 2006. Inedible producers in food webs: controls on stoichiometric food quality and composition of grazers. American Naturalist 167:628-637.

Hall, S. R., V. H. Smith, D. A. Lytle, and M. A. Leibold. 2005. Constraints on primary producer $\mathrm{N}: \mathrm{P}$ stoichiometry along $\mathrm{N}: \mathrm{P}$ supply ratio gradients. Ecology 86:1894-1904.

Healey, F. P. 1985. Interacting effects of light and nutrient limitation on the growth rate of Synechococcus linearis (Cyanophycaeae). Journal of Phycology 21:134-146.

Hessen, D. O., and B. Bjerkeng. 1997. A model approach to plankton stoichiometry and consumer-resource stability. Freshwater Biology 38:447-472.

Hessen, D. O., P. J. Færøvig, and T. Andersen. 2002. Light, nutrients, and $\mathrm{P}: \mathrm{C}$ ratios in algae: grazer performance related to food quality and quantity. Ecology 83:1886-1898.

Hillebrand, H., G. de Montpellier, and A. Liess. 2004. Effects of macrograzers and light on periphyton stoichiometry. Oikos 106:93-104.

Hillebrand, H., and M. Kahlert. 2001. Effect of grazing and nutrient supply on periphyton biomass and nutrient stoichiometry in habitats of different productivity. Limnology and Oceanography 46:1881-1898.

Huisman, J., and F. J. Weissing. 1995. Competition for nutrients and light in a mixed water column: a theoretical analysis. American Naturalist 146:536-564.

Klausmeier, C. A., E. Litchman, T. Daufresne, and S. A. Levin. 2004a. Optimal nitrogen-to-phosphorus stoichiometry of phytoplankton. Nature 429:171-174.

Klausmeier, C. A., E. Litchman, and S. A. Levin. 2004b. Phytoplankton growth and stoichiometry under multiple nutrient limitation. Limnology and Oceanography 42:1463-1470.

Kunz, T. J., and S. Diehl. 2003. Phytoplankton, light, and nutrients in a gradient of mixing depths: a field test of producer-resource theory. Freshwater Biology 48:1050-1063.

Legendre, P., and L. Legendre. 1998. Numerical ecology. Elsevier, New York, New York, USA.

Leibold, M. A. 1996. A graphical model of keystone predation: effects of productivity on abundance, incidence, and ecological diversity in communities. American Naturalist 147: 784-812.

Loladze, I., Y. Kuang, and J. J. Elser. 2000. Stoichiometry in producer-grazer systems: linking energy flow with element cycling. Bulletin of Mathematical Biology 62:1137-1162.

Loladze, I., Y. Kuang, J. J. Elser, and W. F. Fagan. 2004. Coexistence of two predators on one prey mediated by stoichiometry. Theoretical Population Biology 65:1-15.

McCauley, E. 1984. The estimation of the abundance and biomass of zooplankton in samples. Pages 228-265 in J. A. Downing and F. H. Rigler, editors. A manual on methods for the assessment of secondary productivity in fresh waters. Blackwell Scientific, Oxford, UK.

Moe, S. J., R. S. Stelzer, M. R. Forman, W. S. Harpole, T. Daufresne, and T. Yoshida. 2005. Recent advances in ecological stoichiometry: insights for population and community ecology. Oikos 109:29-39.

Muller, E. B., R. M. Nisbet, S. A. L. M. Kooijman, J. J. Elser, and E. McCauley. 2001. Stoichiometric food quality and herbivore dynamics. Ecology Letters 4:519-529.

Passarge, J., S. Hol, M. Escher, and J. Huisman. 2006. Competition for nutrients and light: Stable coexistence, 
alternative stable states, or competitive exclusion? Ecological Monographs 76:57-72.

Pennak, R. W. 1978. Fresh-water invertebrates of the United States. Second edition. John Wiley and Sons, New York, New York, USA.

Prepas, E. E., and F. H. Rigler. 1982. Improvements in quantifying the phosphorus concentration in lake water. Canadian Journal of Fisheries and Aquatic Sciences 39:822-829.

Rhee, G.-Y. 1978. Effects of N:P atomic ratios and nitrate limitation on algal growth, cell composition and nitrate uptake. Limnology and Oceanography 23:10-25.

Sarnelle, O. 2003. Non-linear effects of an aquatic consumer: causes and consequences. American Naturalist 161:478-496.

Smith, V. H. 1979. Nutrient dependence of primary productivity in lakes. Limnology and Oceanography 24:1051-1064.

Smith, V. H. 1983. Low nitrogen to phosphorus ratios favor dominance by blue-green algae in lake phytoplankton. Science 221:669-671.

Smith, V. H. 1986. Light and nutrient effects on the relative biomass of blue-green algae in lake phytoplankton. Canadian Journal of Fisheries and Aquatic Sciences 43:148-153.

Sommer, F., B. Santer, C. Jamieson, T. Hansen, and U. Sommer. 2003. Daphnia population growth but not moulting is a substantial phosphorus drain for phytoplankton. Freshwater Biology 48:67-74.

Sommer, U. 1992. Phosphorus-limited Daphnia: intraspecific facilitation instead of competition. Limnology and Oceanography 37:966-973.

Sterner, R. W. 1986. Herbivores' direct and indirect effects on algal populations. Science 231:605-607.

Sterner, R. W. 1990. The ratio of nitrogen to phosphorus resupplied by herbivores: zooplankton and the algal competitive arena. American Naturalist 136:209-229.

Sterner, R. W. 1993. Daphnia growth on varying quality of Scenedesmus: mineral limitation of zooplankton. Ecology 74 : 2351-2360.

Sterner, R. W., J. Clausen, W. Lampert, and T. Weisse. 1998. Carbon: phosphorus stoichiometry and food chain production. Ecology Letters 1:146-150.
Sterner, R. W., and J. J. Elser. 2002. Ecological stoichiometry: the biology of elements from molecules to the biosphere. Princeton University Press, Princeton, New Jersey, USA.

Sterner, R. W., J. J. Elser, E. J. Fee, S. J. Guilford, and T. H. Chrzanowski. 1997. The light: nutrient relation in lakes: the balance of energy and materials affects ecosystem structure and process. American Naturalist 150:663-684.

Tessier, A. J., and P. Woodruff. 2002. Cryptic trophic cascade along a gradient of lake size. Ecology 83:1263-1270.

Tilman, D. 1982. Resource competition and community structure. Princeton University Press, Princeton, New Jersey, USA.

Tilman, D., R. Keislijng, R. Sterner, S. S. Kilham, and F. A. Johnson. 1986. Green, blue-green, and diatom algae: taxonomic differences in competitive ability for phosphorus, silicon, and nitrogen. Archiv fur Hydrobiologie 106:473485 .

Urabe, J., J. Clasen, and R. W. Sterner. 1997. Phosphoruslimitation of Daphnia: Is it real? Limnology and Oceanography 42:1436-1443.

Urabe, J., J. J. Elser, M. Kyle, T. Yoshida, T. Sekino, and Z. Kawabata. 2002a. Herbivorous animals can mitigate unfavorable ratios of energy and material supplies by enhancing nutrient recycling. Ecology Letters 5:177-185.

Urabe, J., M. Kyle, W. Makino, T. Yoshida, T. Andersen, and J. J. Elser. 2002b. Reduced light increases herbivore production due to stoichiometric effects of light/nutrient balance. Ecology 83:619-627.

Urabe, J., and R. W. Sterner. 1996. Regulation of herbivore growth by the balance of light and nutrients. Proceedings of the National Academy of Sciences (USA) 93:8465-8469.

Urabe, J., and Y. Watanabe. 1992. Possibility of $\mathrm{N}$ or $\mathrm{P}$ limitation for planktonic cladocerans: an experimental test. Limnology and Oceanography 37:244-251.

Vanni, M. J. 2002. The role of animals in nutrient cycling in freshwater ecosystems. Annual Review of Ecology and Systematics 33:341-370.

\section{APPENDIX A}

More methods and results of regression, correlation, and ANOVA (Ecological Archives E088-073-A1).

\section{APPENDIX B}

Description of model system (Ecological Archives E088-073-A2).

\section{APPENDIX C}

Depth and the light: nutrient hypothesis (Ecological Archives E088-073-A3). 